\title{
ANALISIS PEMASARAN BAWANG MERAH DI KECAMATAN PLAMPANG KABUPATEN SUMBAWA
}

\author{
ANALYSIS OF SHALLOT MARKETING IN PLAMPANG SUBDISTRICT \\ SUMBAWA REGENCY
}

\author{
Yunita*, Efendy, Nuning Juniarsih
}

Program Studi Agribisnis, Fakultas Pertanian Universitas Mataram, Mataram, Indonesia

*Email Penulis Korespondensi: yunita@gmail.com

\begin{abstract}
ABSTRAK
Tujuan penelitian ini (1) untuk mengetahui saluran pemasaran bawang merah di Kecamatan Plampang Kabupaten Sumbawa, (2) untuk menganalisis efesiensi pemasaran bawang merah di Kecamatan Plampang Kabupaten Sumbawa, dan (3) untuk meganalisis biaya yang dikeluarkan oleh masing - masing saluran pemasaran bawang merah di Kecamatan Plampang Kabupaten Sumbawa. Penentuan responden secara random sampling sebanyak 30 orang dan responden lembaga pemasaran ditentukan dengan menggunakan snowball sampling pada 4 orang pedagang pengumpul, 3 orang pedagang pengecer dan 1 orang pedagang Antar Pulau. Sumber data yang digunakan dalam penelitian ini meliputi efesiensi pemasaran, dan analisis perilaku pasar. Hasil penelitian ini menunjukan bahwa (1) Ada 2 saluran pemasaran bawang merah yang ada di Desa Brang Kolong Kecamatan Plampang Kabupaten Sumbawa yaitu: Petani - Pedagang Pengumpul - Pedagang Antar Pulau - Konsumen dan Petani - Pedagang Pengecer - Konsumen Akhir. (2) Pemasaran bawang merah di Desa Brang Kolong Kecamatan Plampang Kabupaten Sumbawa cukup efesien karena total biaya terhadap total nilai produk berkisar antara 3,32\% $4,86 \%$. Terhadap saluran pemasaran II lebih efisien dari saluran pemasaran I dan bahwa perubahan harga ditingkat pedagang ditransimisikan dengan sempurna ke tingkat petani sehingga pemasaran bawang merah tersebut efesien. (3) Besarnya total biaya pemasaran, total marjin pemasaran dan total keuntungan pada saluran pemasaran I yaitu dengan total biaya pemasaran yg dikeluarkan sebesar Rp. $1.406(7,79 \%)$, total margin pemasaran sebesar Rp. 10.594 (57,14\%), dan total keuntungan sebesar Rp. 12.000 (66,11\%). Sedangkan pada saluran pemasaran II yaitu total biaya pemasaran sebesar Rp. 724 (4,53\%), total margin pemasaran sebesar Rp. $4.276(26,72 \%)$ dan total keuntungan sebesar Rp. 5.000 (31,25\%) yang dikeluarkan dan diterima pada pemasaran bawang merah di Desa Brang Kolong Kecamatan Plampang Kabupaten Sumbawa..
\end{abstract}

Kata Kunci: Pemasaran Bawang Merah, Efesiensi Pemasaran, Analisis Perilaku Pasar

\begin{abstract}
The purpose of this study (1) to determine the onion marketing channel in Plampang District, Sumbawa Regency, (2) to analyze the efficiency of shallot marketing in Plampang District of Sumbawa Regency, and (3) to analyze the costs incurred by each channel marketing of shallots in the district of Plampang, Sumbawa Regency. The determination of respondents by random sampling of 30 people and respondents of marketing institutions determined using snowball Sampling on 4 traders, 3 retailers and 1 inter-island trader. Data sources used in this study include marketing efficiency, and analysis of market behavior. The results of this study indicate that (1) There are 2 onion marketing channels in Brang Kolong Village, Plampang District, Sumbawa Regency, namely: Farmers - Collecting Traders - Inter-Island Traders Consumers and Farmers - Retailers - End Consumers. (2) Onion marketing in Brang Kolong Village, Plampang District, Sumbawa Regency is quite efficient because the total cost of the total product value ranges from $3.32 \%-4.86 \%$. Towards marketing channel II, it is more efficient than marketing channel I and that changes in prices at the trader level are perfectly transmitted to the farm level so that the marketing of shallots is efficient. (3) The amount of total marketing costs, total marketing margins and total profits in marketing channel I, namely the total marketing costs incurred of Rp. 1,406 (7.79\%), total marketing margin of Rp. 10,594 (57.14\%), and total profits of Rp. 12,000 (66.11\%). Whereas in marketing channel II, the total marketing cost is Rp. 724 (4.53\%), total marketing margin of Rp. 4,276 $(26.72 \%)$ and total profits of Rp. 5,000 (31.25\%) issued and received on the marketing of shallots in Brang Kolong Village, Plampang District, Sumbawa Regency.
\end{abstract}

Keywords: Shallot Marketing, Marketing Efficiency, Market Behavior Analysis 


\section{PENDAHULUAN}

Sektor pertanian merupakan sektor yang memiliki peran yang sangat penting dalam pemulihan ekonomi bangsa dan pembangunan ekonomi jangka panjang. Sektor pertanian paling banyak menyerap tenaga kerja dari pada sektor-sektor lainnya. Pada tahun 2014, tenaga kerja di bidang sektor pertanian berjumlah 38.973 .033 dari 114.628.026 jiwa yang bekerja. Sektor pertanian terdiri atas beberapa subsektor yaitu subsektor tanaman pangan, hortikultura, perkebunan, perikanan, peternakan, dan kehutanan (Badan Pusat Statistik Indonesia, 2014).

Salah satu kegiatan dibidang pertanian yang memberikan kontribusi adalah usahatani hortikultura. Kontribusi hortikultura terhadap manusia dan lingkungan cukup besar. Manfaat produk hortikultura bagi manusia diantaranya adalah sebagai sumber pangan dan gizi, pendapatan keluarga, pendapatan negara, sedangkan bagi lingkungan adalah rasa estetika, konservasi genetik dan sebagai penyangga kelestarian alam (Ashari, 1995:3).

Pangan merupakan kebutuhan manusia yang paling azasi, sehingga ketersediaan pangan bagi masyarakat harus selalu terjamin (Septiadi et al, 2016). Manusia dengan segala kemampuannya selalu berusaha mencukupi kebutuhannya dengan berbagai cara. Ketahanan pangan merupakan kondisi terpenuhinya pangan bagi rumah tangga yang tercemin dari ketersediaan pangan yang cukup, baik jumlah maupun mutunya, aman, merata, dan terjangkau. Ketahanan pangan merupakan hal yang penting dan strategis. Komoditas pangan seperti beras, sayur - sayuran, dan buah - buahan mengalami surplus (Nababan N I, 2008).

Komoditas hortikultura di Indonesia memiliki prospek pengembangan yang sangat baik karena memiliki nilai ekonomi yang tinggi serta potensi pasar yang terbuka lebar, baik didalam negeri maupun di luar negeri (Septiadi \& Nursan, 2021). Sayur-sayuran telah memberikan sumbangan dalam sektor pertanian, dapat dilihat dalam meningkatnya kontribusi sub sektor hortikultura terhadap PDB (produk domestik bruto nasional) dari tahun ke tahun (Tanaya et al, 2021). Disamping itu, budidaya tanaman hortikultura tropis dan subtropis sangat memungkinkan untuk dikembangkan di Indonesia karena tersedianya keragaman agroklimat dan karakteristik lahan serta sebaran wilayah yang luas. Pengembangan komoditas hortikultura haruslah dilakukan secara profesional yaitu dengan adanya pembangunan seimbang antara aspek pertanian, bisnis, dan jasa penunjang (Zulkarnain, 2009:8).

Saat ini, banyak komoditi hortikultura yang menjadi komoditi unggulan dan salah satu komoditinya adalah bawang merah. Tanaman bawang merah (Allium ascalonicum L.) merupakan tanaman hortikultura yang paling potensial memberikan keuntungan bagi petani dibanding tanaman hortikultura lainnya karena permintaan akan bawang merah yang cenderung meningkat dan budidaya bawang merah yang dapat diusahakan pada lahan yang sempit. Bawang merah merupakan salah satu jenis sayuran pelengkap dan bumbu pelezat masakan yang sangat diperlukan oleh hampir seluruh masyarakat Indonesia (Tim Bina Karya Tani, 2008:1).

Provinsi Nusa Tenggara Barat sebagai salah satu daerah penghasil bawang merah yang pengembangannya sejak pelita I sampai sekarang melalui program intensifikasi dan ekstensifikasi. Usahatani bawang merah sebagai salah satu komoditi andalan diusahakan di semua kabupaten di provinsi NTB, dan kabupaten Bima merupakan penghasil bawang merah terbesar yaitu sebesar 89.076 ton/tahun, Sumbawa di urutan kedua yaitu sebesar 8.745 ton/tahun, dan untuk kabupaten Dompu menghasilkan bawang merah sebesar 1.673 ton/tahun, dan untuk kabupaten Lombok Barat, Lombok 
Tengah, Lombok Utara, Sumbawa Barat, Kota Bima, dan Kota Mataram untuk produksi pertahunnya tidak sampai 1000 ton/tahun (Badan Pusat Statistik NTB, 2015).

Di Kabupaten Sumbawa perkembangan produksi bawang merah mengalami fluktuasi sejak tahun 2014 sampai tahun 2018, pada tahun 2014 jumlah produksi pertahunnya sebesar 11.904 ton, dan mengalami peningkatan pada tahun 2015 jumlah produksi pertahunnya sebesar 17.642 ton, dan pada tahun 2016 jumlah produksi pertahunnya sebesar 23.935, dan pada tahun 2017 mengalami peningkatan yang sangat besar sebesar 33.949,80 ton dan mengalami penurunan pada tahun 2018 sebesar 28.768 ton (Badan Pusat Statistik NTB, 2019).

Menurut Cahyono (2009:11), permintaan terhadap komoditi bawang merah akan terus meningkat sejalan dengan kenaikan jumlah penduduk, kenaikan tingkat pendapatan, dan kesadaran masyarakat akan pentingnya kesehatan. Selama ini harga bawang merah dikendalikan pada mekanisme pasar sehingga menyebabkan naik turunnya harga komoditi bawang merah.

Permasalahan dalam usahatani bawang merah adalah keterbatasan modal dan sarana produksi, kecilnya luas areal garapan, keterbatasan teknologi budidaya, rendahnya ketersediaan tenaga kerja terampil dan pemasaran yang belum berpihak sepenuhnya kepada petani. Pemasaran hasil pertanian menempati posisi yang sangat penting dari sistem produksi, karena dalam usahatani komersial, pemasaran hasil akan sangat menentukan keberhasilan dan kelestarian usahatani yang dikelola tersebut.

Petani memiliki waktu yang tepat untuk menanam agar dapat diperoleh harga jual yang tinggi atau yang sesuai dengan keinginannya sehingga dapat menghasilkan keuntungan optimal baik bagi petani maupun lembaga pemasaran yang terlibat.

Petani bawang merah di Kecamatan Plampang Kabupaten Sumbawa pada umumnya memiliki dua alternatif dalam memasarkan hasilnya yaitu dengan cara pertama langsung menjual kekosumen dan yang kedua menjualnya ke lembaga - lembaga pemasaran.

Resiko yang sering dihadapi petani bawang merah adalah petani bawang merah belum mampu mengendalikan harga jual yang kadang melambung tinggi dan di lain waktu justru melorot hingga harga terendah. Kalau di kaji lebih jauh, fluktuasi harga bawang merah tersebut sesungguhnya sebagai dampak para pedagang pengumpul yang selama ini menguasai jalur distribusi tersebut.

Proses pemasaran perlu untuk dicermati karena akan mempengaruhi kesejahteraan petani melalui pendapatan yang diterima dari harga jual produk pertanian. Pada proses pemasaran yang buruk membuat petani mengalami kerugian karena harga yang diterima petani lebih kecil dibandingkan biaya yang dikeluarkan petani untuk melakukan usaha tani.

Dari 24 kecamatan di Kabupaten Sumbawa, kecamatan yang melakukan usahatani bawang merah yang produksinya tinggi adalah Kecamatan Plampang sebesar 25.273,90 ton menjadikan kabupaten tersebut sebagai salah satu sentra produksi bawang merah Indonesia, hal ini menjadi peluang bagi Kabupaten Sumbawa Besar untuk meningkatkan kesejahteraan petani bawang merah. Proses pemasaran bawang merah sangat penting untuk dicermati karena mempengaruhi kesejahteraan petani melalui pendapatan yang diterima dari harga jual produk pertanian. Dibutuhkan proses pemasaran yang efisien agar dapat mensejahterkan petani melalui pendapatannya. Proses pemasaran yang efisien akan memberikan kelayakan harga yang diterima petani atas harga di tingkat eceran, salah satunya dapat disebabkan oleh jumlah pelaku pemasaran yang terlibat tidak terlalu banyak. Banyaknya pelaku pemasaran berpengaruh terhadap tinggi rendahnya harga di tingkat eceran karena terdapat keterpaduan harga antar pelaku pemasaran yang terlibat. 
Usaha perbaikan dibidang pemasaran sangat diperlukan, karena usaha peningkatan produksi saja tidak mampu untuk meningkatkan pendapatan petani bila tidak didukung dan dihubungkan dengan situasi pasar. Tingginya biaya akan berpengaruh terhadap harga eceran pada konsumen dan harga di tingkat petanisebagai produsen. Suatu sistem pemasaran dianggap efisien apabila mampu menyampaikan hasil-hasil dari produsen kepada konsumen dengan harga yang murah dan mampu mengadakan pembagian yang adil dari keseluruhan harga yang dibayarkan konsumen akhir kepada semua pihak yang ikut didalam kegiatan produksi dan pemasaran barang tersebut. Adil dalam hal ini adalah pemberian balas jasa fungsi-fungsi pemasaran sesuai sumbangannya masingmasing (Mubyarto, 1989: 166).

Efisiensi pemasaran sangatlah penting supaya masing-masing lembaga mendapatkan keuntungan sesuai apa yang telah mereka keluarkan (input). Jika tidak ada efisiensi pemasaran maka ada pihak atau lembaga yang dirugikan karena mungkin lembaga tersebut telah mengeluarkan input lebih besar dibandingkan dengan keuntungan yang didapatkannya dan begitu juga sebaliknya, lembaga yang mengeluarkan input lebih kecil tetapi mendapatkan keuntungan yang besar, dan akan terjadilah kesenjangan keuntungan yang diperoleh (Hamid, 1994:88).

Berdasarkan uraian diatas maka perlu ditinjau pemasaran (marketing mix) dan biaya yang dikeluarkan oleh masing - masing lembaga pemasara Oleh karena itu dilakukan penelitian tentang "Analisis Pemasaran Bawang Merah di Keacamatan Plampang Kabupaten Sumbawa”. Berdasarkan uraian tersebut, maka rumusan masalah dalam penilitian ini adalah : 1.)Bagaimana saluran pemasaran bawang merah di Kecamatan Plampang Kabupaten Sumbawa 2.) Bagaimana efesiensi pemasaran bawang merah di Kecamatan Plampang Kabupaten Sumbawa ? 3.) Bagaimana biaya yang dikeluarkan oleh masing - masing saluran pemasaran bawang merah di Kecamatan Plampang Kabupaten Sumbawa?

Oleh sebab itu, artikel ini bertujuan: 1.) Untuk mengetahui saluran pemasaran bawang merah di Kecamatan Plampang Kabupaten Sumbawa. 2.) Untuk menganalisis efesiensi pemasaran bawang merah di Kecamatan Plampang Kabupaten Sumbawa. 3.) Untuk menganalisis biaya yang dikeluarkan oleh masing - masing saluran pemasaran bawang merah di Kecamatan Plampang Kabupaten Sumbawa

\section{METODE PENELITIAN}

Metode yang digunakan dalam penelitian ini adalah metode diskriptif merupakan metode yang tertuju pada pengkajian masalah yang ada pada saat sekarang dengan cara mengumpulkan data, menyusun, menganalisa, mengintepretasikan data dan menarik suatu kesimpulan. Pengumpulan data dilakukan dengan cara survei, yaitu data dikumpulkan dari sejumlah individu anggota populasi (sample) dalam waktu yang bersamaan untuk menggambarkan keadaan populasi dengan menggunakan daftar pertanyaan yang telah disusun sebelumnya. Data yang dikumpulkan melalui wawancara langsung dengan petani (Soerakhmad, 1990). Unit Analisis Yang menjadi objek analisis dalam penelitian ini adalah petani dan pedagang - pedagang yang terlibat di dalam pemasaran bawang merah di Desa Brang Kolong Kecamatan Plampang Kabupaten Sumbawa. Penentuan daerah penelitian dilakukan berdasarkan jumlah produksi terbanyak adalah Desa Brang kolong yang mewakili kecamatan Plampang. Bahwa daerah tersebut merupakan daerah sentra produksi bawang merah di NTB, baik dalam hal luas tanam, luas panen, produksi dan produktivitas per luas panen. Responden dalam penelitian ini adalah sebanyak 30 petani dan Penentuan responden ditentukan secara 
Random Sampling dengan alasan bahwa semua petani di Desa Brang Kolong Kecamatan Plampang mempunyai kesempatan yang sama untuk dijadikan resonden. Sedangkan untuk penentuan responden lembaga pemasaran dilakukan dengan menelusuri lembaga pemasaran yang terlibat dalam saluran pemasaran bawang merah mulai dari tingkat petani bawang merah sampai ke konsumen akhir dan dilakukan secara Snowball Sampling yaitu penentuan responden yang semula kecil kemudia terus membesar seperti bola salju. Jenis data yang dalam penelitian ini yaitu data kuanlitatif dan data kuantitatif. Data kuantitatif adalah data yang diukur atau dihitung secara langsung dengan angka atau bilangan, seperti jumlah produksi yang dijual, harga, dan lain - lain. Data kualitatif adalah data yang tidak dapat diukur dalam bentuk bilangan atau angka, tetapi lebih banyak berupa kalimat, narasi, cerita, dekripsi, dokumen atau gambaran mengenai penelitian.

Adapun sumber data yang digunakan dalam penelitian ini yaitu data primer dan data sekunder. Data primer adalah data yang diperoleh secara langsung dari responden dengan menggunakan wawancara yang berpedoman pada daftar pertanyaan yang disiapkan dan Data sekunder adalah data yang diperoleh dari sumber yang sudah ada yaitu literature atau refrensi dari Dinas atau Instansi yang ada hubungannya dengan penelitian ini.

\section{Analisis Data}

Untuk mengetahui saluran pemasaran bawang merah dan fungsi - fungsi yang dilakukan oleh masing - masing lembaga pemasaran bawang merah di Kecamatan Plampang Kabupaten Sumbawa digunakan metode analisis deskriptif, yaitu dengan menganalisis saluran pemasaran dan fungsi - fungsi yang dilakukan setiap lembaga lembaga yang terlibat dalam saluran pemasaran bawang merah, yaitu mulai dari produsen (petani bawang merah) hingga ke konsumen akhir.

\section{Farmer Share (FS)}

Menurut (Mubyarto dalam Yogi dan Rantaningtyas, 2012: 118).

$$
F s \equiv \frac{H p}{H k} \times 100 \%
$$

Keterangan:

Fs = Farmer Share

$\mathrm{Hp}=$ Harga yang diterima petani

$\mathrm{Hk}=$ Harga yang diterima konsumen

Semakin tinggi nilai farmer share, maka semakin besar bagian yang diterima petani. Berarti semakin efisien pemasaran di Kecamatan Plampang Kabupaten Sumbawa.

\section{Margin Pemasaran (Market Margin)}

$$
M j i=\text { Psi }- \text { Pbi Atau } M j i=b t i+i
$$

Ketarangan:

Mji=Margin pada lembaga pemasaran tingkat ke $-\mathrm{i}$

Psi $=$ Harga jual pada pemasaran tingkat ke $-\mathrm{i}$

$\mathrm{Pbi}=$ Harga beli pada pemasaran tingkat $\mathrm{ke}-\mathrm{i}$

bti = Biaya pemasaran tingkat $\mathrm{ke}-\mathrm{i}$

$\mathrm{i}=$ Keuntungan pemasaran tingkat ke $-\mathrm{i}$ 


\section{Share Harga}

$$
S P=\frac{P_{f}}{P_{r}} \times 100 \%
$$

Keterangan:

$\mathrm{SP}=$ Bagian harga yang diterima petani

Pf = Harga ditingkat produsen

$\operatorname{Pr}=$ Harga ditingkat konsumen

Kriteria keputusan:

1. Jika $X>60 \%$ berarti penyampaian hasil produksi bawang merah dari produsen ke konsumen adalah dengan biaya yang rendah (Efesien)

2. Jika $X<60 \%$ berarti biaya penyampaian hasil produksi bawang merah dari produsen ke konsumen dengan biaya yang tinggi (tidak efisien).

Untuk mengetahui volume Penjualan dapat dilihat dari jumlah produksi bawang merah yang dijual produsen maupun lembaga pemasaran yang dinyatakan dalam kilogram.

Untuk mengetahui perilaku pasar digunakan analisis keterpaduan pasar secara vertikal (Efendy dalam Sumarni, 2005). dilakukan dengan menggunakan elastisitas transmisi harga model Cobb Douglas dengan rumus sebagai berikut:

$$
\begin{aligned}
& \mathrm{Pf}=\mathrm{A} \mathrm{Pr}{ }^{\beta} \\
& \log \mathrm{Pf}=\log \mathrm{A}+\beta \log \operatorname{Pr}
\end{aligned}
$$

Keterangan:

$\mathrm{Pf}=$ Harga di tingkat petani $(\mathrm{Rp} / \mathrm{Kg})$

$\operatorname{Pr}=$ Harga di tingkat konsumen $(\mathrm{Rp} / \mathrm{Kg})$

$\mathrm{A}=$ Intersep

$\mathrm{B}=$ Koefisien elastisitas transmisi harga

Hipotesis:

1.) Ho $: b=1$, harga di tingkat pedagang pengecer ditrasmisikan dengan sempurna ke tingkat petani.

2.) Hi : $b \neq 1$, harga di tingkat pedagang pengecer tidak ditransmisikan dengan sempurna ke tingkat petani.

Pengujian hipotesis dilakukan dengan membandingkan antara $\mathrm{t}$ - hitung dengan $\mathrm{t}-$ tabel dengan rumus sebagai berikut:

$$
\begin{aligned}
& \mathrm{t}-\text { hitung }=\frac{b-1}{S e(b)} \\
& \mathrm{t}-\text { tabel }=\mathrm{ta} / 2(\mathrm{n}-\mathrm{k}-1)
\end{aligned}
$$

kriteria keputusan:

1. jika $\mathrm{t}$ - hitung $>\mathrm{t}$ - tabel maka Ho ditolak, berarti harga ditingkat pedagang tidak ditransmisikan dengan sempurna karna di tingkat petani atau pemasaran bawang merah belum efisien. 
2. Jika $\mathrm{t}$ - hitung $\leq \mathrm{t}$ - tabel maka Ho diterima, berarti perubahan harga ditingkat pedagang ditransimisikan dengan sempurna ke tingkat petani atau pemasaran bawang merah efisien

\section{HASIL DAN PEMBAHASAN}

\section{Saluran Pemasaran}

Dalam penelitian ini Saluran pemasaran yang juga disebut dengan saluran distribusi atau saluran pemasaran. Perdagangan dapat digambarkan sebagai suatu route atau jalur. Berdasarkan hasil penelitian pemasaran bawang merah di Desa Brang Kolong Kecamatan Plampang Kabupaten Sumbawa. Untuk mengetahui lebih jelasnya, saluran pemasaran disajikan pada Gambar 1.

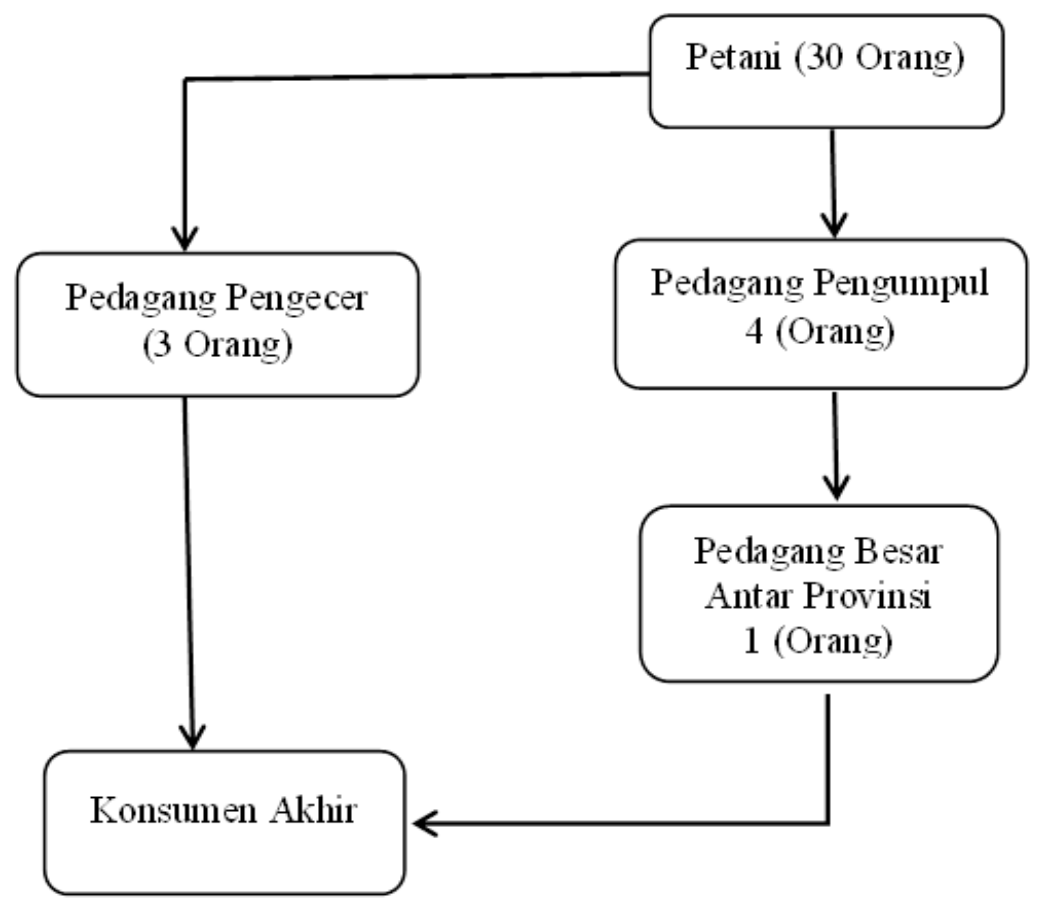

Gambar 1. Saluran Pemasaran

Dari kedua saluran pemasaran tersebut, pada Gambar 1. dapat di jelaskan saluran pemasaran di Kecamatan Plampang Kabupaten Sumbawa khususnya di Desa Brang Kolong yaitu:

1. Petani - Pedagang Pengumpul - Pedagang Besar Antar Provinsi.

2. Petani - Pedagang Pengecer - Konsumen Akhir.

Di Kecamatan Plampang Kabupaten Sumbawa khususnya di Desa Brang Kolong sebanyak 30 petani yang berperan dalam menyalurkan produksi bawang merah ke pedagang pengumpul, dari 30 petani tersebut menjual bawang merahnya ke pedagang pengumpul yang memiliki volume penjualan sebesar 125 ton, dari 30 petani tersebut menjual bawang merahnya di ke empat pedagang pengumpul pada saluran ini, alasanya karena pedagang pengumpul mendatangi langsung petani untuk membeli hasil produksi bawang merahnya, sehingga langsung terjual semuanya dalam waktu yang singkat. 


\section{Efesiensi Pemasaran}

Analisis efisiensi pemasran dilakukan untuk menentukan saluran pemasaran bawang merah yang efisien, di mana ukuran efisiensi menggunakan indikator efisiensi operasional. Analisis efisiensi operasional dapat digunakan untuk menentukan efisiensi sistem dari sisi kuantitatif dengan menggunakan analisis margin pemasaran, presentase margin dan share harga dapat dilihat sebagai berikut:

\section{Rasio Biaya dengan Nilai Produk}

Rasio biaya dengan nilai produk dapat di golongkan efesien jika biaya pemasaran lebih rendah dari pada nilai produk yang dipasarkan, semakin rendah biaya pemasaran dari nilai produk yang dipasarkan semakin efisien melaksanakan pemasaran (Soekartawi, 1997).

Tabel 1. Rasio Biaya dengan Nilai Produk Bawang Merah pada Masing-masing Saluran dan Lembaga Pemasaran

\begin{tabular}{llrrr}
\hline No & \multicolumn{1}{c}{ Saluran Pemasaran } & $\begin{array}{c}\text { Harga Jual } \\
(\mathrm{Rp} / \mathrm{Kg})\end{array}$ & $\begin{array}{c}\text { Total Biaya } \\
\text { Pemasaran } \\
(\mathrm{Rp} / \mathrm{Kg})\end{array}$ & $\begin{array}{r}\text { Efisien Lembaga } \\
\text { Pemasaran }(\%)\end{array}$ \\
\hline 1 & Saluran Pertama: & 16.000 & - & - \\
& $\begin{array}{l}\text { Petani } \\
\text { Pedagang Pengumpul }\end{array}$ & 19.000 & 7.300 & 45,62 \\
& $\begin{array}{l}\text { Pedagang Besar } \\
\text { Provinsi Antar }\end{array}$ & 28.000 & 406 & 2,54 \\
\hline 2 & Saluran Kedua: & & & \\
& Petani & & - & 4,53 \\
\hline
\end{tabular}

Sumber: Data Primer diolah (2020)

Saluran Pemasaran I

$$
\text { Fs } \begin{aligned}
& =100 \% \\
& =100 \% \\
& =57,14 \%
\end{aligned}
$$

Saluran Pemasaran II

$$
\text { Fs } \begin{aligned}
& =100 \% \\
& =100 \% \\
& =76,19 \%
\end{aligned}
$$

Berdasarkan tabel 2 dan perhitungan Farmer Share bahwa saluran pemasaran bawang merah pada saluran pemasaran II sebesar 76,19\% lebih efisien dari saluran pemasaran I sebesar $57,14 \%$. Hal ini terjadi karena pada saluran II lembaga pemasaran yang terlibat dalam saluran pemasaran ini hanya satu. 
Tabel 2. Margin Pemasaran dan Share Harga Pemasaran Bawang Merah

\begin{tabular}{|c|c|c|c|}
\hline \multirow{2}{*}{ No. } & \multirow{2}{*}{ Pelaku Pasar } & \multicolumn{2}{|c|}{ Saluran Pemasaran } \\
\hline & & Saluran I (Rp/Kg) & Saluran II (Rp/Kg) \\
\hline \multirow[t]{2}{*}{1} & Petani/Produsen & & \\
\hline & a. Harga Jual & 16.000 & 16.000 \\
\hline \multirow[t]{9}{*}{2} & Pedagang Pengumpul (PP) & & \\
\hline & a. Harga Beli & 16.000 & \\
\hline & b. Biaya Pemasaran & $1.000(8,33 \%)$ & - \\
\hline & 1. Biaya Buruh & 250 & - \\
\hline & 2. Biaya Transportasi & 700 & \\
\hline & 3. Biaya Karung & 50 & - \\
\hline & c. Harga Jual & 19.000 & \\
\hline & d. Keuntungan Pemasaran & $2.000(16,67 \%)$ & \\
\hline & e. Margin Pemasaran(\%) & $3.000(25 \%)$ & \\
\hline \multirow[t]{6}{*}{3} & Pedagang Besar (PB) & & \\
\hline & a. Harga Beli & 19000 & \\
\hline & b. Biaya Pemasaran & $406(3,38 \%)$ & \\
\hline & c. Harga Jual & 28.000 & \\
\hline & d. Keuntungan Pemasaran & $8.594(73,62 \%)$ & \\
\hline & e. Margin Pemasaran(\%) & $9.000(75 \%)$ & \\
\hline \multirow[t]{6}{*}{4} & Pedagang Pengecer & - & \\
\hline & a. Harga Beli & - & 16.000 \\
\hline & b. Biaya Pemasaran & - & $724(14,48 \%)$ \\
\hline & c. Harga Jual & - & 21000 \\
\hline & d. Keuntungan Pemasaran & - & $4.276(85,52 \%)$ \\
\hline & e. Margin Pemasaran(\%) & - & $5.000(100 \%)$ \\
\hline \multirow[t]{6}{*}{5} & Konsumen Akhir & & \\
\hline & a. Harga Beli & 28.000 & 21.000 \\
\hline & Total Margin Pemasaran $(\%)$ & $12.000(100 \%)$ & $5.000(100 \%)$ \\
\hline & Total Biaya Pemasaran (\%) & $1.406(11,71 \%)$ & $724(14,48 \%)$ \\
\hline & Total Keuntungan (\%) & $10.594(90,29 \%)$ & $4.276(85,52 \%)$ \\
\hline & Share Harga $(\%)$ & $57,14 \%$ & $76,19 \%$ \\
\hline
\end{tabular}

Sumber: Data Primer diolah (2020)

\section{Margin Pemasaran}

Margin pemasaran adalah perbedaan harga di antara tingkat lembaaga dalam sistem pemasaran atau perbedaan antara jumlah yang diterima produsen atas produk pertanian yang diperjual belikan.

Tabel 3. Margin Pemasaran pada Saluran Pemasaran Bawang Merah

\begin{tabular}{|c|c|c|c|c|c|}
\hline No & $\begin{array}{c}\text { Saluran } \\
\text { Pemasaran }\end{array}$ & Pelaku Pasar & Biaya (\%) & $\begin{array}{c}\text { Keuntungan } \\
(\%)\end{array}$ & Margin (\%) \\
\hline \multirow[t]{4}{*}{1} & Saluran I & Petani & - & - & - \\
\hline & & Pedagang & 8,33 & 16,67 & 25 \\
\hline & & Pengumpul & & & \\
\hline & & $\begin{array}{l}\text { Pedagang Antar } \\
\text { Pulau }\end{array}$ & 3,38 & 73,62 & 75 \\
\hline \multirow[t]{3}{*}{2} & Saluran II & Petani & - & & - \\
\hline & & Pedagang Pengecer & 14,48 & 85,52 & 100 \\
\hline & & Konsumen & - & & - \\
\hline
\end{tabular}

Sumber: Data Primer diolah (2020) 
Berdasarkan Tabel 3, pada saluran I pemasaran bawang merah di Desa Brang Kolong Kecamatan Plampang Kabupaten Sumbawa, dapat dilihat lembaga yang paling efesien adalah pedagang pengumpul karena margin dan keuntungan lebih kecil sedangkan untuk biayanya tinggi, sehingga lembaga pemasaran yang paling efesien adalah lembaga pengumpul di bandingan lembaga pemasaran lainnya. Hal ini dikarenakan pedagang pengumpul menguasai pemasaran bawang merah tanpa ada pedagang lainnya.

\section{Share Harga}

Besarnya biaya yang diterima petani/produsen dengan harga yang diterima oleh konsumen pada setiap saluran pemasaran dan disajikan pada tabel 4.

Tabel 4. Bagian Harga yang Diterima Petani Pada Saluran Pemasaran Bawang Merah

\begin{tabular}{|c|c|c|c|c|c|}
\hline \multirow{4}{*}{ No } & \multirow{4}{*}{$\begin{array}{c}\text { Saluran } \\
\text { Pemasaran }\end{array}$} & \multirow{2}{*}{\multicolumn{2}{|c|}{$\begin{array}{c}\text { Harga Rata - rata } \\
(\mathrm{Rp} / \mathrm{Kg})\end{array}$}} & \multirow{3}{*}{$\begin{array}{c}\text { Share Harga } \\
(\%)\end{array}$} & \multirow{2}{*}{$\begin{array}{c}\text { Kriteria } \\
\text { Keputusan } \\
\end{array}$} \\
\hline & & & & & \\
\hline & & Tingkat & Tingkat & & \\
\hline & & Petani & Konsumen & & \\
\hline 1 & Saluran I & 16.000 & 28.000 & $57,14 \%$ & Tidak Efesien \\
\hline 2 & Saluran II & 16.000 & 21.000 & $76,19 \%$ & Efesien \\
\hline
\end{tabular}

Sumber: Data Primer diolah (2020)

Berdasarkan Tabel 4. share harga pada saluran I dan saluran II dalam pemasaran bawang merah di Desa Brang Kolong Kecamatan Plampang Kabupaten Sumbawa adalah $57,14 \%$ dan $76,19 \%$. Sehingga dapat diketahui bahwa saluran pemasaran I memiliki nilai share harga dibawah $60 \%$, sehingga dapat dikatakan tidak efesien dan pada saluran pemasaran II dikatakan efesien karna nilai share harga di atas $60 \%$.

\section{Perilaku Pasar}

Untuk mengetahui perilaku pasar dalam pemasaran bawang merah di Desa Brang Kolong Kecamatan Plampang Kabupaten Sumbawa yaitu dengan menggunakan alat analisis keterpaduan pasar secara vertikal menggunakan elastisitas transmisi harga model Cobb Douglas.

\section{Analisis Keterpaduan Pasar Secara Vertikal}

Hasil analisis regresi model Cobb Douglas diperoleh persamaan sebagai berikut:

$$
\begin{aligned}
& \mathrm{Pf} \quad=1,215 \mathrm{Pr}^{0,499} \\
& \log \mathrm{Pf}=\log 1,215+0,499 \log \operatorname{Pr} \\
& \mathrm{Se} \quad=(0,151)+(0,002)
\end{aligned}
$$

Tabel 5. Analisis Regresi Model Double Logaritma

\begin{tabular}{clc}
\hline No. & \multicolumn{1}{c}{ Uraian } & Nilai \\
\hline 1 & t-hitung & $-1,219$ \\
2 & t-tabel & 6,592 \\
3 & Coefficients & 0,499 \\
4 & Standard Error & 0,002 \\
5 & Hipotesis & Ho diterima \\
\hline
\end{tabular}

Sumber: Data Primer diolah (2020) 
Setelah dilakukan pengujian, maka hasil dari bawang merah yang dipasarkan memiliki t-hitung lebih kecil dari t-tabel $(6,592)$ pada taraf nyata 5\%. Maka Ho diterima sehingga dapat disimpulkan bahwa perubahan harga ditingkat pedagang ditransimisikan dengan sempurna ke tingkat petani. Nilai koefisien sebesar 0,499 artinya ditransmisikan Rp.0,499 ke tingkat petani. Sehingga pemasaran bawang merah tersebut dikatakan efesien.

\section{KESIMPULAN DAN SARAN}

\section{Kesimpulan}

Berdasarkan tujuan dan hasil pembahasan, maka dapat diambil beberapa kesimpulan sebagai berikut:

1. Ada 2 saluran pemasaran bawang merah yang ada di Desa Brang Kolong Kecamatan Plampang Kabupaten Sumbawa yaitu: Petani - Pedagang Pengumpul Pedagang Antar Pulau - Konsumen dan Petani - Pedagang Pengecer - Konsumen Akhir.

2. Pemasaran bawang merah di Desa Brang Kolong Kecamatan Plampang Kabupaten Sumbawa cukup efesien karena total biaya terhadap total nilai produk berkisar antara 3,32\% - 4,86\%. Terhadap saluran pemasaran II lebih efisien dari saluran pemasaran I dan bahwa perubahan harga ditingkat pedagang ditransimisikan dengan sempurna ke tingkat petani sehingga pemasaran bawang merah tersebut efesien.

3. Besarnya total biaya pemasaran, total marjin pemasaran dan total keuntungan pada saluran pemasaran I yaitu dengan total biaya pemasaran yg dikeluarkan sebesar Rp. 1.406 (7,79\%), total margin pemasaran sebesar Rp. 10.594 (57,14\%), dan total keuntungan sebesar Rp. 12.000 (66,11\%). Sedangkan pada saluran pemasaran II yaitu total biaya pemasaran sebesar Rp. 724 (4,53\%), total margin pemasaran sebesar Rp. 4.276 (26,72\%) dan total keuntungan sebesar Rp. 5.000 (31,25\%) yang dikeluarkan dan diterima pada pemasaran bawang merah di Desa Brang Kolong Kecamatan Plampang Kabupaten Sumbawa.

\section{Saran}

Saran yang diberikan dalam penelitian ini adalah:

1. Sebaiknya petani mencari informasi perkembangan harga, sehingga petani memiliki acuan dalam menentukan harga jual.

2. Untuk mengatasi fluktuasi harga bawang merah, sebaiknya pemerintah menetapkan harga dasar pada bawang merah

\section{DAFTAR PUSTAKA}

Badan Pusat Statistik NTB. (2014). NTB Dalam Angka. Kantor Perwakilan BPS Mataram: Mataram.

Badan Pusat Statistik NTB. (2015). NTB Dalam Angka. Kantor Perwakilan BPS Mataram: Mataram.

Badan Pusat Statistik NTB. (2019). NTB Dalam Angka. Kantor Perwakilan BPS Mataram: Mataram.

Ivony Anissa. (2017). Analisis Pemasaran Bawang Merah di Kecamatan Cimenyan Kabupaten Bandung Provinsi Jawa Barat [Skripsi]. Institut Pertanian Bogor: Bogor. 
Mubyarto. (1977). Pengantar Ekonomi Pertanian. LP3ES: Jakarta.

Septiadi, D., \& Nursan, M. (2021). Optimasi Produksi Usaha Tani Sebagai Upaya Peningkatan Pendapatan Petani Sayuran Di Kota Mataram. Agrifo: Jurnal Agribisnis Universitas Malikussaleh, 5(2), 87-96.

Septiadi, D., Harianto, H., \& Suharno, S. (2016). Dampak Kebijakan Harga Beras dan Luas Areal Irigasi Terhadap Pengentasan Kemiskinan di Indonesia. Jurnal Agribisnis Indonesia (Journal of Indonesian Agribusiness), 4(2), 91-106.

Soekartawi. (2002). Prinsip Dasar Manajemen Pemasaran Hasil - hasil Pertanian Teori dan Aplikasinya. PT. Raja Grapindo Persada: Jakarta.

Sumaryani. (2005). Pola Produksi Dan Perilaku Pemasaran Bawang Merah di Kecamatan Belo Kabupaten Bima [Skripsi]. Fakultas Pertanian Universitas Mataram: Mataram.

Tanaya, I. G. L. P., Rosmilawati, R., Hidayati, A., \& Septiadi, D. (2021). Analisis Risiko Produksi Spesialisasi Tanaman Hortikultura di Kabupaten Lombok Utara (Analysis of the Risk of Production for Horticultural Specialties in North Lombok Regency). Prosiding SAINTEK, 3, 315-327. 